\title{
A Sun Tracking PV System Equipped Greenhouse Control System for Educational Purpose
}

\author{
Kee Hwan Kim \\ Department of Electronic Engineering, Semyung University, Korea \\ khkim@semyung.ac.kr
}

Keywords: greenhouse control system, solar energy, sun tracking photovoltaic system

\begin{abstract}
The greenhouse control system for educational purpose is designed based on a personal computer. This system should observe and control the growth conditions for crops in both plastic film and glass greenhouses. In this contribution puts emphasis on construction of greenhouse control system by personal computer under the aim of creating safer, more effective and more economical services. This system is developed for the requirements of the intelligent greenhouse control system and is powered by solar energy. A photovoltaic system with sun tracking module is used for the greenhouse control system.
\end{abstract}

\section{Introduction}

Nowadays many personal computers are distributed in everyday life. These computers have powerful CPUs and very fast peripheral connecters such as USB or IEEE 1394. But usually these computers are used as internet connector or game player or word processor. In this distribution we want to increase the effectiveness of personal computer use in agricultural or horticultural. One of possibilities is to control for a greenhouse.

To control a greenhouse is to control environmental parameters in greenhouse. Controlled environments may be as simple as saran-covered shade houses or as complex as growth chambers. Although greenhouses are probably the most common example of a controlled environment used in agricultural/ horticultural production, the type of controlled environment or system that is needed depends upon the climate, time of year, crops being produced and the environmental parameters that must be controlled.

In this contribution puts emphasis on construction of automatic-controlled greenhouse system with powered by photovoltaic system for an educational purpose.

\section{Parameters of Interest in Horticultural Production}

\section{Greenhouse Structural Components}

Many factors need to be considered when designing the support structure of a greenhouse. The objective in designing a greenhouse structure is to maximize light transmittance (i.e. minimize obstructions to light entry) while providing adequate support. Other considerations in the greenhouse structural design include minimizing exposed surface area, limitations of heating and cooling systems, maximizing open space for automation and maximizing uniformity within the structure.

Figure 1 shows a typical Quonset greenhouse with roll-up side vent system.

\section{Greenhouse Heating and Cooling System}

Greenhouses may utilize central heating systems or localized heating systems. Central heating systems generate heat in one location and distribute that heat to many locations. Localized heating systems are located in the greenhouse or greenhouse section that they are responsible for heating. For large operations, a central heating system may be more efficient. However, the cost of installation and maintenance of a centralized heating system can be high. For smaller operations, this expense may be 
hard to justify. However, the size of the boiler unit, the fuel source, size of the operation and maintenance costs all must be considered when deciding whether to use a centralized or localized heating system.

Greenhouse glazing materials allow short wavelength radiation (i.e. visible light) to pass through but long wavelength radiation such as infrared (heat) is trapped inside the greenhouse. The temperature inside of a greenhouse may be up to $17^{\circ} \mathrm{C}\left(30^{\circ} \mathrm{F}\right)$ higher than the ambient temperature outside of the greenhouse (hence, the greenhouse effect). Because of this property, greenhouses may require both summer and winter cooling systems.

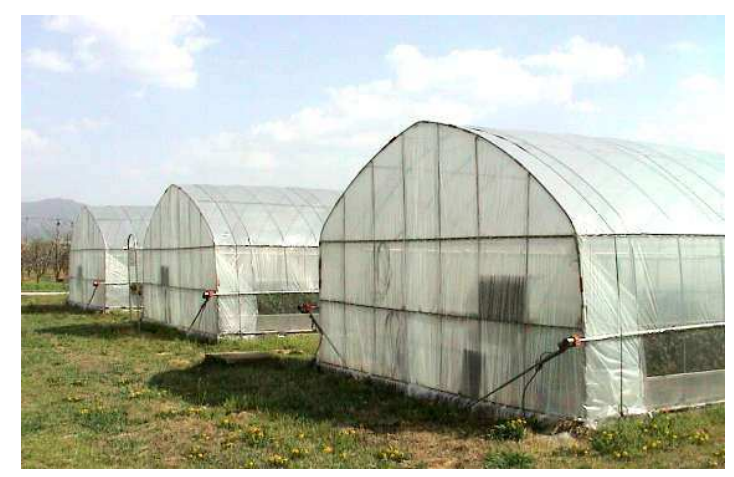

Fig. 1. Quonset Greenhouse with Polyethylene film

\section{- Summer Cooling Systems}

Passive venting - High summer temperatures result in the need for constant heat removal from the greenhouse. This is usually accomplished by replacing existing air in the greenhouse with cooler air from outside of the structure. If outside temperatures are low enough, and if temperatures in the greenhouses are not too high, warm air may be passively exhausted through roof vents. The upward and outward movement of warm air pulls in cool air from side vents. Although this system is most effective in the spring and fall, it is limited in its effectiveness for summer cooling to high elevations and coastal areas.

Fan-and-Mist System - This is the most common type of active-cooling system used in commercial greenhouses. The system takes advantage of the latent heat of evaporation. More specifically, as liquid water evaporates, it absorbs energy from the environment (i.e. surrounding air). This results in a lowering of the temperature of the surrounding air.

Winter Cooling Systems

In some areas of the country, high light levels or fluctuating temperatures might necessitate cooling even during winter days. Additionally, during spring and fall months, heating may be required at night and early mornings while some cooling may be required during the day.

The passive cooling system discussed above is one method that may be used for this type of cooling need. Another system utilizes a fan and louvered vent placed in the gable and combined with a polyethylene tube extended the length of the greenhouse in the gable. The inlet vent is louvered and opens only when the fan turns on. There is an additional set of louvered vents at the opposite end of the greenhouse that allows warm greenhouse air to escape while cooler outside air is forced into the structure. The cool air is forced through the polyethylene tube to allow for a more even distribution of the cool air. In some cases, a unit heater may be used in conjunction with this system. The unit heater is placed in front of the louvered inlet. If heat is needed, the louver and vents are closed. The heater draws in air from within the greenhouse, heats it and forces the warm air through the polyethylene distribution tube. If cooling is needed, the louvered vent and exhaust vent open, and the unit heater fan turns on to force cool air from outside into the polyethylene tube. Of course, during cooling, only the fan on the unit heater is engaged, not the flame box. 
During spring and fall, temperatures are cool at night and rise during the day. During these seasons, the cooling system may be integrated so that as temperature rises, passive cooling is utilized (vents are opened). As the temperature continues to rise, the fans will turn on to actively bring in cooler air from outside. As the temperature continues to rise, the top and side vents close and the pumps turn on and begin feeding water to the pads. This cyclic or integrated approach helps to reduce cooling costs.

\section{Hardware Construction of the system}

The whole system consists of personal computer, some sensors, actuators and one interface card, which can connect the personal computer and sensors. The automatic-controlled system based on a personal computer contains two principal parts: Control Unit, and Power Supply Unit. First, we'll discuss about hardware construction of the system.

Fig. 2 shows the construction of the hardware system.

\section{Control Unit}

The control unit integrates all signals that were received and transmitted, which include the sensor signals. In the control unit diverse sensors are used, such as temperature sensor, humidity sensor, and wind velocity sensor and so on. These sensors are connected with sensor signal conversion circuit. In this signal conversion unit the signals of the sensor can be amplified and A/D converted. The converted and amplified signal is transmitted to the interface card.

On the interface card we have used the MAX232 chip, one of the most widely used for serial communication and 8 bit one chip microprocessor PIC16F877A. It can be used for both memory mapped and peripheral I/O. The PIC16F877A is a 40-pin DIP chip. It has five separately accessible ports, A, B, C, D, and E. More important, one can program the individual ports of the PIC16F877A to be input or output, and change them dynamically. The port $\mathrm{A}$ is used for wind direction and wind velocity sensors. The port $\mathrm{B}$ is used for input signals of actuators. The port $\mathrm{C}$ is used for many functions like as serial communication function and actuator operation signals. The vent position will be detected through the port D. The temperature of the inner and outer of greenhouse is measured through port E.

For the sensor data acquisition, sensors are connected to interface card. On the interface card, sensor data can be converted to digital value by ADC in microprocessor PIC16F877A. The converted data will be transferred to PC through the serial port RS232.

\section{Power Supply Unit}

For the educational purpose in this paper, it is proposed tiny solar tracking system with four CDS sensors, the system designed as the normal line of the solar cell always runs parallel the ray of the sun, and are used two RC servo motors and deals with the economical position tracking system development for the standalone PV system.

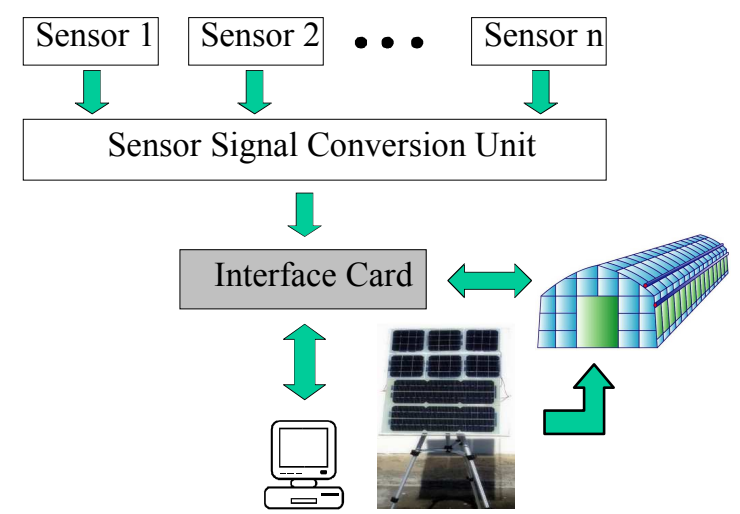

Fig. 2. Construction of the hardware system 


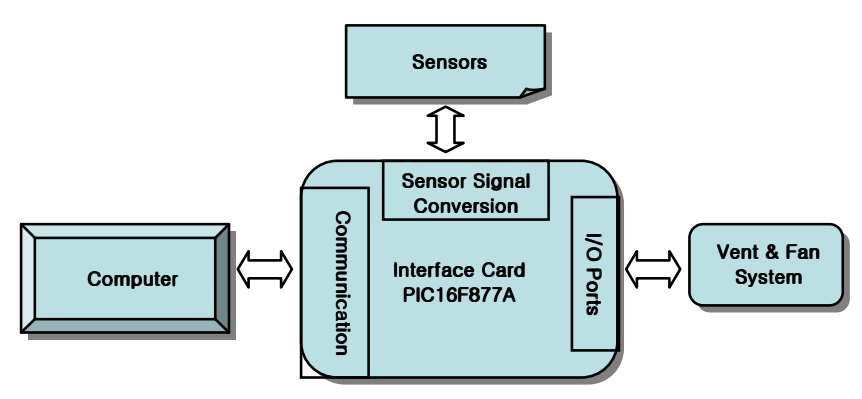

Fig. 3. Interface Card

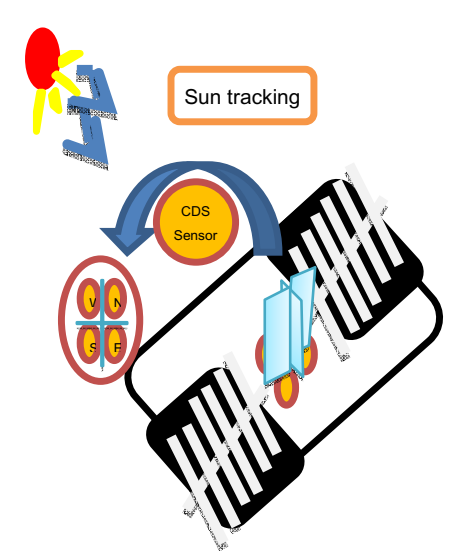

Fig. 4. Sun Tracking System

\section{Software Construction of the system}

The vent control system is programmed by LabVIEW and C-language for PIC16F877A. For the monitoring of green house, LabVIEW software is used. LabVIEW is a graphical programming environment to develop sophisticated measurement, test, and control systems using intuitive graphical icons and wires that resemble a flowchart.

The whole program is composed with several modules. Each module has its own function. If the rain sensor is released, should close the side vent. If the inner temperature is too high, the cooling system will be turned on with cooling algorithm.

The control algorithm for automatic ventilation is developed by [1]. In this contribution Park and Lee's control algorithm is used. In this algorithm are concerned included vent opening level, opening sequence, wind direction and control interval according to the difference ambient and set up temperatures.

The GUI screen is composed of three sub windows. The first window shows the status of the greenhouse. This window tells us with graphically which vent is opened or not as well as how much the vent is opened. Also this window gives us the information which apparatus is active or not. The second window is for crops. To set the optimal environmental condition one can use already saved data some important parameters such as temperature, humidity in hard disk. This data file can be edited with the given editor window. The last window shows the optimal parameters and actual data from ambient sensors, which are installed in and outside of the greenhouse.

\section{Conclusion}

In this contribution an automatic controlled greenhouse based on a personal computer for educational purpose is introduced. This system can be designed very easy, fast, and flexible. For this control system diverse sensors are used. Also interface with programmable device is handled and how to apply each sensor used in this interface system to control a greenhouse. Also here shows how to take 
signals from sensors as data of computer for greenhouse control system. Finally the taken signals of each sensor are evaluated by software. The evaluated parameters are set automatically for an optimal environment to grow a crop. A cooling or heating algorithm for greenhouse is also introduced. The vent control system is programmed by LabVIEW and C. This system is developed for the requirements of the intelligent greenhouse control system and is powered by solar energy. A photovoltaic system with sun tracking module is used for the greenhouse control system.

\section{References}

[1] J. H. Kim, C. S. Kim, K. H. Goo, K. M. Lee, A Study on Automated Greenhouse using Microcomputer, The Korean Agricultural Machinery Institute, vol. 20 (1995), 162-172.

[2] S. Abdallah, S. Nijmeh, Two axes sun tracking system with PLC control, Energy Conversion and Management 45 (2004) 1931-1939

[3] H.J. Tantau, Adaptive control of greenhouse climate, Acta Horticulturae, 148(1984), 277-285.

[4] O.S. Kwon, A Study on an Efficiency of Industrial Education by Using Automated Greenhouse Based on PC Control, Thesis (2002), Semyung University

[5] Information on http://www.junkyoung.com/

[6] Information on http://www.kweather.co.kr/ 